http://dx.doi.org/10.35381/racji.v6i1.1418

\title{
El maltrato infantil en Ecuador
}

\section{Child abuse in Ecuador}

Juan Carlos Arandia-Zambrano

uq.juanarandia@uniandes.edu.ec

Universidad Regional Autónoma de los Andes, Quevedo

Ecuador

https://orcid.org/0000-0001-7301-5447

Génesis Karolina Robles-Zambrano

uq.genesisrobles@uniandes.edu.ec

Universidad Regional Autónoma de los Andes, Quevedo

Ecuador

https://orcid.org/0000-0002-2965-2091

Kenia Lisbeth Alvarado-Cuenca

dq.kenialac36@uniandes.edu.ec

Universidad Regional Autónoma de los Andes, Quevedo

Ecuador

https://orcid.org/0000-0003-1953-3846

Recepción: 15 de marzo 2021

Revisado: 25 de mayo 2021

Aprobación: 15 de junio 2021

Publicación: 01 de Julio 2021 


\section{Estimado Editor (a):}

El maltrato a menores ha generado gran conmoción en nuestro país, a causa de la influencia desfavorable que esto ocasiona a la mayoría de los niños, que lo perciben en el hogar por parte de sus propios progenitores, madrastras, padrastros, tíos, tías, primos, abuelos, hermanos, entre otros seres allegados y en la escuela o instituciones por sus profesores o instructores que son los encargados en cuidar, proteger y contribuir con ellos empleando métodos pedagógicos y psicológicos; otro aspecto es que los agentes del orden de "La Dirección Nacional de Policía Especializada para Niños, Niñas y Adolescentes" (DINAPEN) que efectúan todo tipo de maltratos a la población infantil, siendo estos los voceros a ofrecerles amparo o protección. Este tipo de daños contribuyen de una manera $u$ otra en la conducta de los menores (niñas y niños) lo cual es la causa primordial que predomina en el desempeño perjudicial de la enseñanza. En este sentido, para Romero Viamonte, Villacís Salazar y Jara Vázquez (2016), manifiesta su preocupación:

Los niños/as sufren violencia en su casa, en la escuela, en las instituciones y en la comunidad. La sufren en aquellos espacios y en lugares que debieran ser de protección y de estímulo a su desarrollo integral, de resguardo y promoción de sus derechos. Los niveles de dependencia del niño hacia el adulto o las instituciones que los están agrediendo, lo dejan en una situación de gran vulnerabilidad. (p.221)

El maltrato infantil, ha aumentado debido a varios factores principalmente uno de ellos es la pandemia del COVID-19, generado varios cambios en la vida cotidiana, por lo cual ha hecho que inclusive muchos de los menores fallezcan producto de esta fatal pandemia, ya que muchos se encontraban con sus defensas bajas, el maltrato en este tiempo se genera debido a que en los hogares existen problemas intrafamiliares, entre conyugues o convivientes, por el cual los menores se encuentran presentes, y muchas de las ocasiones por defender a uno de sus progenitores, salen lesionados de una $u$ otra forma, ya sea física, psicológica, emocional, entre otras. Así mismo, muchos servicios de salud infantil y materna, como los exámenes médicos, las vacunas y la atención prenatal y posnatal, han estado suspendidos en todo el mundo debido a la restricción de los recursos y a la aprensión general a la hora de hacer uso de los servicios de salud por miedo a contagiarse con la COVID-19. (Unicef, 2020) 
A nivel legal y de protección González Cárdenas, et al, (2020) plantean:

En el Ecuador se han dado grandes avances en materia de protección de derechos, los mismos van de la mano de la Constitución del año 2008, en donde se garantiza una sistematización que permite establecer los derechos desde la garantía constitucional. (p.407)

Así mismo estas normas establecidas que están en contra del maltrato y la vulneración infantil en la república ecuatoriana, al respecto se muestra el siguiente cuadro:

\section{Cuadro 1.}

Protección infantil.

\begin{tabular}{|c|c|}
\hline Normativa legal & Artículos \\
\hline $\begin{array}{l}\text { Constitución de la República de Ecuador } \\
\text { (2008) }\end{array}$ & $\begin{array}{l}\text { Artículo 44.- El Estado, la sociedad y la } \\
\text { familia promoverán de forma prioritaria el } \\
\text { desarrollo integral de las niñas, niños y } \\
\text { adolescentes, y asegurarán el ejercicio } \\
\text { pleno de sus derechos; se atenderá al } \\
\text { principio de su interés superior y sus } \\
\text { derechos prevalecerán sobre los de las } \\
\text { demás personas. } \\
\text { Las niñas, niños y adolescentes tendrán } \\
\text { derecho a su desarrollo integral, } \\
\text { entendido como proceso de crecimiento, } \\
\text { maduración y despliegue de su intelecto y } \\
\text { de sus capacidades, potencialidades y } \\
\text { aspiraciones, en un entorno familiar, } \\
\text { escolar, social y comunitario de } \\
\text { afectividad y seguridad. Este entorno } \\
\text { permitirá la satisfacción de sus } \\
\text { necesidades sociales, afectivo- } \\
\text { emocionales y culturales, con el apoyo de } \\
\text { políticas intersectoriales nacionales y } \\
\text { locales. } \\
\text { Artículo 45.- Las niñas, niños y } \\
\text { adolescentes gozarán de los derechos } \\
\text { comunes del ser humano, además de los } \\
\text { específicos de su edad. El Estado } \\
\text { reconocerá y garantizará la vida, incluido } \\
\text { el cuidado y protección desde la } \\
\text { concepción. Las niñas, niños y } \\
\text { adolescentes tienen derecho a la } \\
\text { integridad física y psíquica; a su } \\
\text { identidad, nombre y ciudadanía; a la } \\
\text { salud integral y nutrición; a la educación y } \\
\text { cultura, al deporte y recreación; a la }\end{array}$ \\
\hline
\end{tabular}




\begin{tabular}{|c|c|}
\hline & $\begin{array}{l}\text { seguridad social; a tener una familia y } \\
\text { disfrutar de la convivencia familiar y } \\
\text { comunitaria; a la participación social; al } \\
\text { respeto de su libertad y dignidad; a ser } \\
\text { consultados en los asuntos que les } \\
\text { afecten; a educarse de manera prioritaria } \\
\text { en su idioma y en los contextos culturales } \\
\text { propios de sus pueblos y nacionalidades; } \\
\text { y a recibir información acerca de sus } \\
\text { progenitores o familiares ausentes, salvo } \\
\text { que fuera perjudicial para su bienestar. } \\
\text { El Estado garantizará su libertad de } \\
\text { expresión y asociación, el funcionamiento } \\
\text { libre de los consejos estudiantiles y } \\
\text { demás formas asociativas. } \\
\text { Artículo } 46 \text {. Literal 4.- Protección y } \\
\text { atención contra todo tipo de violencia, } \\
\text { maltrato, explotación sexual o de } \\
\text { cualquier otra índole, o contra la } \\
\text { negligencia que provoque tales } \\
\text { situaciones. }\end{array}$ \\
\hline $\begin{array}{l}\text { Convención sobre los Derechos de los } \\
\text { Niños (2002) }\end{array}$ & $\begin{array}{l}\text { Artículo 3, Literal 1.- En todas las medidas } \\
\text { concernientes a los niños que tomen las } \\
\text { instituciones públicas o privadas de } \\
\text { bienestar social, los tribunales, las } \\
\text { autoridades administrativas o los órganos } \\
\text { legislativos, una consideración primordial } \\
\text { a que se atenderá será el interés superior } \\
\text { del niño. } \\
\text { Artículo 19, Literal 1.- Toda violencia, } \\
\text { perjuicio o abuso físico o mental, } \\
\text { descuido o trato negligente, malos tratos } \\
\text { o explotación, mientras que el niño se } \\
\text { encuentre bajo la custodia de sus padres, } \\
\text { de un tutor o de cualquiera otra persona } \\
\text { que le tenga a su cargo. }\end{array}$ \\
\hline Código de la Niñez y Adolescencia (2003) & $\begin{array}{l}\text { Artículo 11.- El interés superior del niño. } \\
\text { El interés superior del niño es un principio } \\
\text { que está orientado a satisfacer el ejercicio } \\
\text { efectivo del conjunto de los derechos de } \\
\text { los niños, niñas y adolescentes; e impone } \\
\text { a todas las autoridades administrativas y } \\
\text { judiciales y a las instituciones públicas y } \\
\text { privadas, el deber de ajustar sus } \\
\text { decisiones y acciones para su } \\
\text { cumplimiento. el interés superior se } \\
\text { Para apreciar el } \\
\text { considerará la necesidad de mantener un } \\
\text { justo equilibrio entre los derechos y } \\
\text { deberes de niños, niñas y adolescentes, }\end{array}$ \\
\hline
\end{tabular}




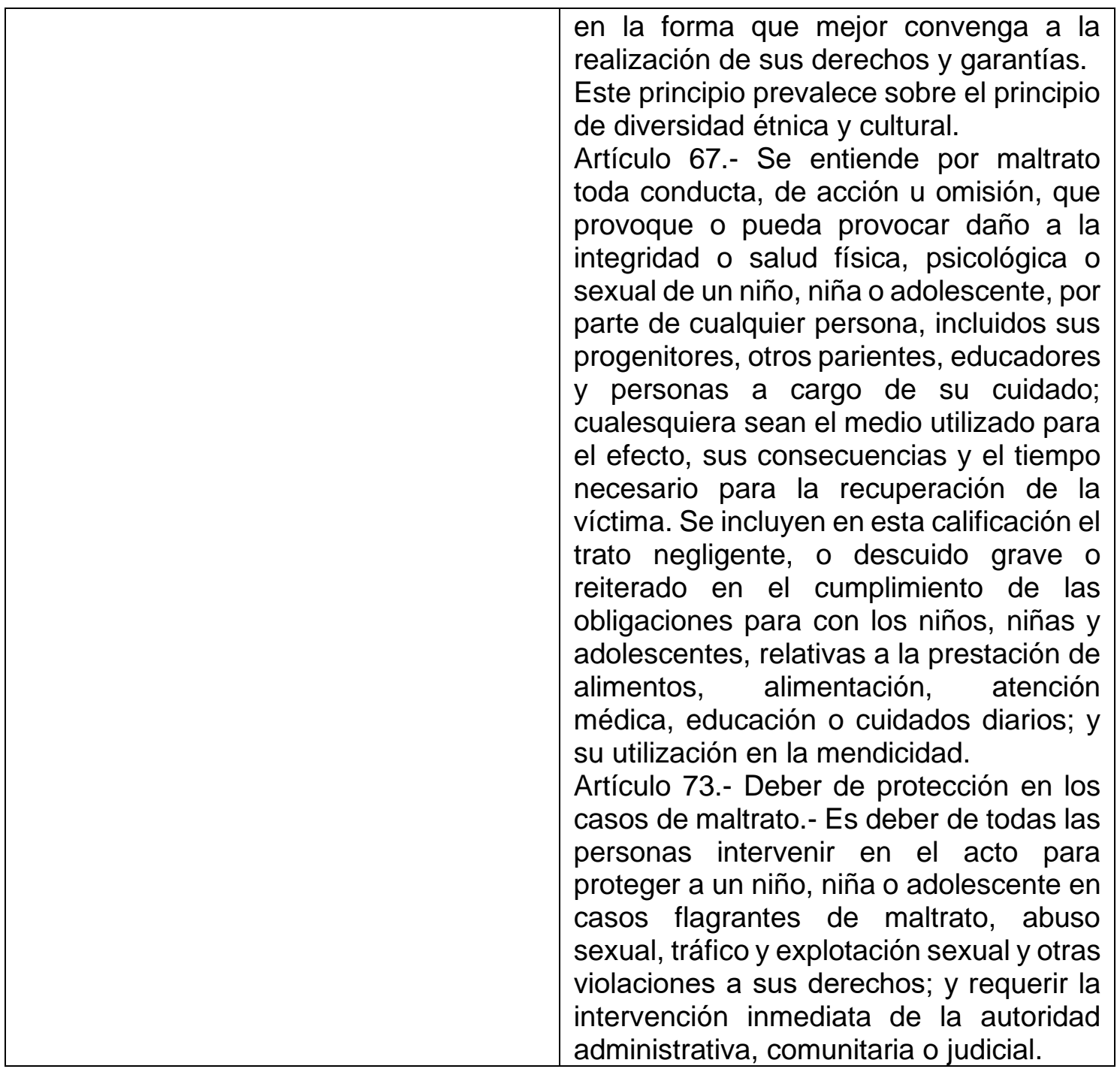

Elaboración: Los autores.

El maltrato infantil en el Ecuador, es una de las formas de violencia mediante la cual nuestra Constitución de la República del Ecuador (2008) en concordancia con la Convención sobre los Derechos de Los Niños (2002) y el Código de Niñez y Adolescencia (2003) han logrado enfatizar ante este mal social que se ha venido generando desde tiempo remotos hasta la actualidad, siendo así que con el pasar de los años estas normativas ecuatorianas han tenido más rigor en contra de quienes cometen este tipo de actos hacia los niños y niñas. 


\section{FINANCIAMIENTO}

No monetario.

\section{AGRADECIMIENTO}

A la Universidad Regional Autónoma de los Andes, Ecuador; por motivar el desarrollo de la Investigación.

\section{REFERENCIAS CONSULTADAS}

Asamblea Nacional Constituyente de la República del Ecuador, (2008). Constitución de la República del Ecuador. Montecristi. Registro Oficial 449 de 20-oct-2008. Recuperado de https://n9.cl/sia

Congreso Nacional. (2003). Código de la niñez y adolescencia. [Childhood and Adolescence Code]. Quito.

Gobierno de la República del Ecuador (s/f) Dinapen al servicio de menores de edad en situación de riesgo. [Dinapen at the service of minors at risk]. Recuperado de: https://n9.cl/giahi

González-Cárdenas, F., Narváez Zurita, C., Guerra-Coronel, M., Erazo Álvarez, J. (2020) Protección para niños, niñas y adolescentes: La protección integral prevista en la constitución ecuatoriana. [Protection for children and adolescents: The integral protection provided for in the Ecuadorian constitution]. Iustitia Socialis. 5(1), 397-414. http://dx.doi.org/10.35381/racji.v5i1.619

Romero Viamonte, K., Villacís Salazar, M., y Jara Vázquez, E. (2016). Maltrato infantil en escuela ecuatoriana de Ambato. [Child abuse in Ecuadorian school in Ambato]. Humanidades Médicas, 16(2), 215-226. Recuperado de: https://n9.cl/bjo6

UNICEF (2002). Convención de Derechos del Niños de las Naciones Unidas. [United Nations Convention on the Rights of the Child]. Madrid: UNICEF.

UNICEF (2020). La COVID-19 podría anular décadas de progresos para poner fin a las muertes infantiles prevenibles, según advierten los organismos. [COVID-19 could undo decades of progress to end preventable child deaths, agencies warn] Recuperado de: https://n9.cl/yjwa6 
Iustitia Socialis. Revista Arbitrada de Ciencias Jurídicas

Año VI. Vol. VI. N 1. Edición Especial. 2021

Hecho el depósito de Ley: FA2016000064 ISSN: 2542-3371

FUNDACIÓN KOINONIA (F.K). Santa Ana de Coro, Venezuela

Juan Carlos Arandia-Zambrano; Génesis Karolina Robles-Zambrano; Kenia Lisbeth Alvarado-Cuenca

2021 por los autores. Este artículo es de acceso abierto y distribuido según los términos y condiciones de la licencia Creative Commons Atribución-NoComercial-Compartirlgual 4.0 Internacional (CC BY-NC-SA 4.0) (https://creativecommons.org/licenses/by-nc-sa/4.0/) 